\title{
Adubação com cama de aviário na produção de milho orgânico em sistema de integração lavoura-pecuária
}

\section{Fertilization with broiler litter in the production of organic corn in integrated crop-livestock}

\author{
Jaqueline Huzar Novakowiski ${ }^{*}$; Itacir Eloi Sandini²; Margarete Kimie Falbo ${ }^{3}$; \\ Anibal de Moraes ${ }^{4}$; Jackson Huzar Novakowiski ${ }^{1}$
}

\section{Resumo}

O experimento foi realizado com o objetivo de avaliar o efeito sobre a cultura do milho em sistema de integração lavoura-pecuária da adubação com cama de aviário na pastagem (inverno) e no milho (verão), como alternativa para a produção orgânica. Os tratamentos de inverno consistiram nas doses de 0 e $5 \mathrm{Mg} \mathrm{ha}^{-1}$ de cama de aviário com e sem pastejo de ovinos e os tratamentos de verão nas doses de $0,1,2,4$ e $8 \mathrm{Mg} \mathrm{ha}^{-1}$ de cama de aviário no milho. A partir dos resultados obtidos, verificou-se que o pastejo não afetou a produtividade de milho no verão. O uso de cama de aviário no inverno apresentou efeito significativo sobre a massa de mil grãos de milho evidenciando efeito residual da adubação, contudo não foi suficiente para proporcionar diferença significativa na produtividade de milho. Houve efeito linear positivo para o número de grãos por fileira e quadrático para a produtividade de milho pelo aumento das doses de cama de aviário no verão. Nas áreas sem pastejo a máxima produtividade de milho seria obtida com aplicação de $9 \mathrm{Mg} \mathrm{ha}^{-1}$ de cama de aviário no verão, ao passo que, esta mesma produtividade seria obtida com $7 \mathrm{Mg} \mathrm{ha}^{-1}$ nas áreas pastejadas, representando uma economia de $2 \mathrm{Mg}$ ha $^{-1}$ de cama de aviário, o que corresponde a $45 \mathrm{~kg} \mathrm{ha}^{-1}$ de nitrogênio. Logo, constatou-se viabilidade técnica pelo uso da cama de aviário na produção de milho em sistema de integração lavoura-pecuária.

Palavras-chave: Zea mays L., sistemas integrados, adubação orgânica

\begin{abstract}
The experiment was carried out with the objective of evaluating the effect on corn crop in crop-livestock integration system of fertilization with chicken litter in the pasture (winter) and in the corn (summer), as alternative to organic production. The winter treatments consisted in the doses of 0 and $5 \mathrm{Mg} \mathrm{ha} \mathrm{a}^{-1}$ of chicken litter, with or without grazing of ovines and the summer treatments in the doses of $0,1,2$, 4 and $8 \mathrm{Mg} \mathrm{ha}^{-1}$ of chicken litter in the corn. From the results obtained, it was checked that the grazing did not affect the grain yield of corn in summer. The use of chicken litter in winter presented significant effect on mass of one thousand grains of corn, evidencing residual effect of fertilization however, it was not sufficient to provide significant difference in corn yield. There was positive linear effect to number of grains per row and quadratic to corn yield by increase of chicken litter levels in summer. In areas without grazing the maximum corn yield would be obtained with application of $9 \mathrm{Mg} \mathrm{ha}^{-1}$ of chicken litter in summer, whereas this same yield would be obtained with $7 \mathrm{Mg} \mathrm{ha}^{-1}$ in grazed areas, representing an economy of $2 \mathrm{Mg} \mathrm{ha}^{-1}$ of chicken litter corresponding to $45 \mathrm{~kg} \mathrm{ha}^{-1}$ of nitrogen. Thus, it was found technical viability by use of chicken litter in corn production in crop-livestock integration system.
\end{abstract}

Key words: Zea mays L., integrated systems, organic fertilization

\footnotetext{
${ }^{1}$ Discente(s) do curso de Agronomia, Universidade Estadual do Centro-Oeste, UNICENTRO, Campus CEDETEG, Guarapuava, PR.E-mail: jaquehuzar@hotmail.com; jacksonhuzar@hotmail.com

${ }^{2}$ Eng $^{\mathrm{o}}$ Agr $^{\mathrm{o}}$, Prof. Dr. do Dept ${ }^{\mathrm{o}}$ de Agronomia, UNICENTRO, Guarapuava, PR. E-mail: isandini@hotmail.com

${ }^{3}$ Médica Veterinária, Prof ${ }^{\mathrm{a}}$. Dr ${ }^{\mathrm{a}}$. do Dept ${ }^{\mathrm{o}}$ de Medicina Veterinária, UNICENTRO, Guarapuava, PR. E-mail: margaretefalbo@ hotmail.com

${ }^{4}$ Eng $^{\text {o }}$ Agr $^{\circ}$, Prof. Dr. do Dept ${ }^{\circ}$ de Fitotecnia e Fitossanitarismo, Universidade Federal do Paraná, UFPR. E-mail: anibalm@ufpr.br

* Autor para correspondência
} 


\section{Introdução}

A demanda por produtos orgânicos é crescente em nível mundial. Entretanto, um dos principais entraves para produção orgânica reside na nutrição e adubação das culturas, principalmente quanto ao aporte de nitrogênio aos sistemas produtivos.

Os sistemas de produção agropecuários originam diversos resíduos orgânicos e sua utilização como fonte de nutrientes às plantas e condicionadores dos solos tem se constituído em uma alternativa interessante para a preservação da qualidade ambiental (MELLO; VITTI, 2002).

Segundo Graciano et al. (2006), as fontes mais comuns de adubo orgânico são representadas pelos adubos verdes, resíduos de culturas, estercos, compostos, entre outros. Entretanto, a escolha do resíduo a ser utilizado está em função de sua disponibilidade, variando entre as regiões e a cultura nas quais se fará seu emprego.

Dentre os resíduos com grande disponibilidade na região Centro-Sul do Paraná, destaca-se aquele proveniente da criação intensiva de aves, denominados de cama de frango, cama de poedeiras ou apenas cama de aviário, que por serem ricos em nutrientes e estarem disponíveis a um baixo custo, podem ser viabilizados pelos produtores na adubação das culturas agrícolas (COSTA et al., 2009).

A integração lavoura-pecuária é uma alternativa para intensificação do uso da terra e aumento da sustentabilidade dos sistemas de produção, principalmente naquelas áreas deixadas em pousio ou destinadas a culturas de cobertura de solo. Nos sistemas orgânicos de produção, a integração entre a produção vegetal e a animal é desejável pela complementaridade decorrente da participação animal no sistema (CRUZ et al., 2006). Uma vez que, o pastejo possibilita a reciclagem de nutrientes ao solo através das fezes e urina dos animais (ASSMANN; ASSMANN; ASSMANN, 2008; BRAZ et al., 2002).
A cultura do milho (Zea mays L.) se destaca no cenário agrícola brasileiro por ser um dos cereais mais produzidos para atender a demanda do mercado do consumidor. Para tanto, deve-se considerar que o nitrogênio é um dos nutrientes exigidos em maior quantidade pelo milho, apresentando os efeitos mais relevantes no aumento da produção de grãos na cultura (SILVA et al., 2005; FERNANDES; LIBARDI; TRIVELIN, 2008).

Assim, tendo em vista o potencial de aproveitamento da cama de aviário e a falta de informações a respeito de sua utilização em sistemas de integração lavoura-pecuária, este trabalho foi realizado com o objetivo de avaliar o efeito residual da adubação com cama de aviário na pastagem durante o período de inverno e a adubação com cama de aviário no milho durante o verão como alternativa para viabilização de um sistema de produção orgânica.

\section{Material e Métodos}

\section{Local do experimento}

O experimento foi realizado no Campus CEDETEG da Universidade Estadual do CentroOeste em Guarapuava (PR) de abril de 2009 a março de 2010. A área experimental localizase nas coordenadas geográficas $25^{\circ} 23^{\prime} 06^{\prime \prime} \mathrm{S}$ e $51^{\circ} 29^{\prime} 31^{\prime \prime} \mathrm{O}$ e está sendo conduzida em sistema de integração lavoura-pecuária desde o ano de 2006, com a ocupação de ovinos no período de inverno em pastagem de aveia e azevém e no verão cultivo de milho e feijão em anos intercalados. $\mathrm{O}$ clima da região é classificado segundo Köppen como $\mathrm{Cfb}$ : clima temperado, com temperatura média no mês mais frio abaixo de $18^{\circ} \mathrm{C}$ (mesotérmico), verões frescos, temperatura média no mês mais quente abaixo de $22^{\circ} \mathrm{C}$ e sem estação seca definida (IAPAR, 2010). 


\section{Caracterização do solo}

O solo da área experimental é do tipo Latossolo Bruno Distroférrico típico (EMBRAPA, 2006). Foi realizada a amostragem de solo em abril de 2009 antes da implantação da pastagem de inverno e sua caracterização química na profundidade de $0-15 \mathrm{~cm}$ para as áreas sem pastejo é a seguinte: $\mathrm{pH}$ em $\mathrm{CaCl}_{2}$ $=5,31 ; 36,98 \mathrm{~g} \mathrm{dm}^{-3}$ de matéria orgânica; $2,24 \mathrm{mg}$ $\mathrm{dm}^{-3}$ de P (Mehlich); 0,31 $\mathrm{cmol}_{\mathrm{c}} \mathrm{dm}^{-3}$ de $\mathrm{K}^{+} ; 3,23$ $\mathrm{cmol}_{\mathrm{c}} \mathrm{dm}^{-3}$ de $\mathrm{Ca}^{+2}$; 5,27 $\mathrm{cmol}_{\mathrm{c}} \mathrm{dm}^{-3} \mathrm{de}^{+2}+\mathrm{Mg}^{+2}$; $0,07 \mathrm{cmol}_{\mathrm{c}} \mathrm{dm}^{-3}$ de $\mathrm{Al}^{+3} ; \mathrm{Al}+\mathrm{H}=4,89 \mathrm{cmol}_{\mathrm{c}} \mathrm{dm}^{-}$ 3; soma de bases $=5,59 \mathrm{cmol}_{\mathrm{c}} \mathrm{dm}^{-3}$; CTC $=10,48$ $\mathrm{cmol}_{\mathrm{c}} \mathrm{dm}^{-3}$. Nas áreas com pastejo a análise química do solo apresentou o seguinte resultado: $\mathrm{pH}$ em $\mathrm{CaCl}_{2}=5,32 ; 40,87 \mathrm{~g} \mathrm{dm}^{-3}$ de matéria orgânica; $2,26 \mathrm{cmol}_{\mathrm{c}} \mathrm{dm}^{-3}$ de P (Mehlich); 0,34 $\mathrm{cmol}_{\mathrm{c}} \mathrm{dm}^{-3}$ de $\mathrm{K}^{+} ; 3,77 \mathrm{cmol}_{\mathrm{c}} \mathrm{dm}^{-3}$ de $\mathrm{Ca}^{+2} ; 5,64 \mathrm{cmol}_{\mathrm{c}} \mathrm{dm}^{-3} \mathrm{de}$ $\mathrm{Ca}^{+2}+\mathrm{Mg}^{+2} ; 0,02 \mathrm{cmol}_{\mathrm{c}} \mathrm{dm}^{-3}$ de $\mathrm{Al}^{+3} ; \mathrm{Al}+\mathrm{H}=4,35$ $\mathrm{cmol}_{\mathrm{c}} \mathrm{dm}^{-3}$; soma de bases $=5,98 \mathrm{cmol}_{\mathrm{c}} \mathrm{dm}^{-3}$; CTC $=10,34 \mathrm{cmol}_{\mathrm{c}} \mathrm{dm}^{-3}$.

\section{Cama de aviário}

A cama de aviário foi proveniente da criação de poedeiras da empresa Agrogen localizada no município de Guarapuava (PR), sendo coletada após a saída das aves, com 52 semanas de alojamento. Uma amostra da cama de aviário foi submetida à análise de sua composição química ao Laboratório de Análises Físico-Químicas da Fundação ABC em Castro (PR) a qual revelou a seguinte composição: $77,03 \%$ de matéria seca; $30,93 \%$ de resíduo mineral; $2,25 \%$ de $\mathrm{N} ; 4,68 \%$ de $\mathrm{P}_{2} \mathrm{O}_{5} ; 3,03 \%$ de $\mathrm{K}_{2} \mathrm{O} ; 12,42 \%$ de $\mathrm{CaO} ; 0,89 \%$ de $\mathrm{MgO} ; 0,23 \%$ de $\mathrm{S} ; 0,22 \%$ de $\mathrm{Zn}$; 0,07\% de Mn; 11,33 mg kg-1 de Fe; 95,68 mg kg-1 de $\mathrm{Cu}$ e 301,90 $\mathrm{mg} \mathrm{kg}^{-1}$ de B.

\section{Fase I-Inverno}

No período de inverno, a área experimental foi manejada com o propósito de estabelecer a base para os tratamentos de verão. Neste período foram implantados quatro sistemas de produção, a saber: 1) com pastejo e com cama de aviário; 2) com pastejo sem cama de aviário; 3 ) sem pastejo com cama de aviário e, 4) sem pastejo sem cama de aviário. $\mathrm{O}$ delineamento experimental utilizado foi de blocos casualizados com 3 repetições. Cada unidade experimental correspondeu a $102 \mathrm{~m}^{2}$.

A semeadura da pastagem foi realizada no dia 15 de abril de 2009, em sistema de semeadura direta, tendo como cultura antecessora o feijoeiro. Foram utilizados $70 \mathrm{~kg} \mathrm{ha}^{-1}$ de sementes de aveia preta (Avena strigosa L.) cultivar IAPAR 61 e $30 \mathrm{~kg} \mathrm{ha}^{-1}$ de azevém comum (Lollium multiflorum Lam.), com profundidade de 1,0 a $1,5 \mathrm{~cm}$ e espaçamento de 0,17 $\mathrm{m}$ entre linhas. Quando fertilizado com cama de aviário a quantidade aplicada no dia da semeadura foi de $5 \mathrm{Mg} \mathrm{ha}^{-1}$.

O período de pastejo correspondeu a 125 dias (20/06/09 a 23/10/09), sendo utilizado o pastejo contínuo de ovinos, com altura de $14 \mathrm{~cm}$. O controle da altura da pastagem foi realizado por meio da técnica de lotações variáveis, "put-andtake" (MOTT; LUCAS, 1952). A quantidade de massa seca do resíduo da pastagem, com e sem pastejo, foi estimada na saída dos animais com a coleta de 4 amostras simples em área de $0,25 \mathrm{~m}^{2}$ compondo uma amostra composta de cada parcela. As amostras foram levadas para secagem em estufa de ventilação forçada de ar por 72 horas a $65^{\circ} \mathrm{C}$, e em seguida efetuou-se sua pesagem para obtenção da massa seca.

\section{Fase II - Verão}

Em sucessão a pastagem, foi realizada a semeadura do milho. O delineamento utilizado foi o de blocos casualizados com parcelas subsubdivididas. A parcela principal consistiu dos tratamentos do período de inverno, na subparcela com e sem pastejo e nas subsubparcelas os tratamentos de verão $\left(0,1,2,4\right.$ e $8 \mathrm{Mg} \mathrm{ha}^{-1}$ de cama de aviário). A unidade experimental apresentou área de $16 \mathrm{~m}^{2}$ (4 linhas x $0,8 \mathrm{~m}$ x $5 \mathrm{~m}$ ), utilizando para avaliação as duas linhas centrais. 
A semeadura do híbrido de milho 30F53 foi efetuada no dia 16/11/09 em sistema de semeadura direta, com espaçamento de $0,8 \mathrm{~m}$ entre linhas. A emergência das plântulas ocorreu 8 dias após a semeadura. O controle das plantas daninhas foi realizado de forma mecânica com capinas. Não foi efetuado controle de pragas e doenças. As variáveis avaliadas foram população final de plantas, índice de espigamento, produtividade, número de fileiras de grãos por espiga, número de grãos por fileira, número de grãos por espiga e massa de mil grãos.

$\mathrm{O}$ ajuste da população foi realizado por meio de desbaste das plantas em estádio fenológico V2 (duas folhas expandidas). Anteriormente a colheita foi feita a contagem das plantas da área útil da parcela para obtenção da população final de plantas. $\mathrm{O}$ índice de espigamento foi obtido pela relação entre o número de espigas e de plantas na área útil da parcela. A colheita do milho foi efetuada em 15/04/10, em seguida efetuando-se a pesagem dos grãos e depois da correção da umidade para 14 $\%$, o valor obtido foi convertido para $\mathrm{kg} \mathrm{ha}^{-1}$. Para avaliação do número de fileiras e grãos por fileira foram utilizadas dez espigas, colhidas em sequência, da segunda linha central de cada parcela, obtendose também o número de grãos por espiga. A massa de mil grãos foi estimada a partir da pesagem de 300 grãos de cada parcela.

\section{Análise Estatística}

Os resultados das avaliações foram submetidos à análise de variância. Quando os resultados revelaram significância a 5 ou $1 \%$ de probabilidade, as médias do fator qualitativo (tratamentos de inverno) foram comparadas pelo teste Tukey a 5\% de probabilidade por meio do programa estatístico Sisvar. Para o fator quantitativo (tratamentos de verão), foram ajustadas regressões polinomiais entre os níveis de cama de aviário (variável independente) e as demais variáveis dependentes buscando-se o modelo que melhor expressasse essa relação com auxílio da planilha eletrônica Microsoft Excel 2007.
Foi testado modelo linear e quadrático e a escolha foi baseada na significância (menor que 5\%) e no coeficiente de determinação.

\section{Resultados e Discussão}

Nas áreas com pastejo o resíduo da forragem foi significativamente inferior em relação às áreas não pastejadas (Tabela 1), o que já era esperado em decorrência do consumo da área foliar das plantas pelos animais em pastejo. Entretanto, a aplicação de $5 \mathrm{Mg} \mathrm{ha}^{-1}$ da cama de aviário na pastagem não apresentou efeito significativo sobre a massa seca de resíduo. Ao comparar este resultado com aqueles relatados por Assmann et al. (2009), em que foi obtido aumento linear na produção de massa seca de pastagem de aveia branca e azevém em função do aumento da dose de esterco líquido de suínos até $120 \mathrm{~m}^{3} \mathrm{ha}^{-1}$ (504 $\mathrm{kg} \mathrm{ha}^{-1}$ de N) é de se esperar que talvez uma dose maior do que $5 \mathrm{Mg} \mathrm{ha}^{-1}(112,5 \mathrm{~kg}$ $\mathrm{ha}^{-1}$ de N) de cama de aviário possibilitaria diferença significativa na massa seca de resíduo, uma vez que Menezes et al. (2009), ao utilizarem adubação com resíduos orgânicos de cama de aviário $\left(10 \mathrm{Mg} \mathrm{ha}^{-1}\right)$ e de dejetos de suínos $\left(150 \mathrm{~m}^{3} \mathrm{ha}^{-1}\right)$ conseguiram substituir a adubação mineral em Brachiaria brizantha, Panicum maximum e Cynodun dactylon.

Tabela 1. Massa seca de resíduo de aveia preta e azevém $\left(\mathrm{kg} \mathrm{ha}^{-1}\right)$ para os diferentes tratamentos no inverno. Guarapuava, PR, 2011.

\begin{tabular}{cccc}
\hline \multirow{2}{*}{ Pastejo } & \multicolumn{3}{c}{ Cama de aviário } \\
\cline { 2 - 4 } & Sem & Com & Média \\
\hline Sem & $4353 \mathrm{a} A$ & $5668 \mathrm{a} \mathrm{A}$ & $5011 \mathrm{a}$ \\
Com & $1850 \mathrm{~b} \mathrm{~A}$ & $1969 \mathrm{~b} \mathrm{~A}$ & $1910 \mathrm{~b}$ \\
\hline Média & $3102 \mathrm{~A}$ & $3818 \mathrm{~A}$ & 3460 \\
\hline
\end{tabular}

Coeficiente de variação $=25,7 \%$. Médias seguidas por letras distintas, maiúsculas nas linhas e minúsculas nas colunas, diferem entre si pelo Teste de Tukey a $5 \%$ de probabilidade.

Fonte: Elaboração dos autores.

De acordo com o resumo da análise de variância (Tabela 2) verificou-se que o número de fileiras de grãos por espiga não foi afetado por nenhum dos 
fatores de variação. O pastejo afetou a população de plantas e a produtividade. Os tratamentos de verão apresentaram efeito sobre a produtividade e número de grãos por fileira, ao passo que, os tratamentos de inverno afetaram a massa de mil grãos. A interação pastejo $\mathrm{x}$ tratamentos de verão $(\mathrm{P} \times \mathrm{V})$ e tratamentos de inverno $\mathrm{x}$ tratamentos de verão (I x V) apresentaram efeito sobre a massa de mil grãos.

Tabela 2. Resumo da análise de variância com os fatores de variação, graus de liberdade e quadrados médios para cada variável avaliada no experimento. Guarapuava, PR, 2011.

\begin{tabular}{|c|c|c|c|c|c|c|c|}
\hline \multirow[b]{2}{*}{$\begin{array}{l}\text { Fator de } \\
\text { variação }\end{array}$} & \multirow[b]{2}{*}{ GL } & \multicolumn{6}{|c|}{ Quadrados Médios } \\
\hline & & $\begin{array}{l}\text { População } \\
\left.\text { (plantas ha }^{-1}\right)\end{array}$ & $\begin{array}{l}\text { Índice de } \\
\text { espigamento } \\
\text { (espigas por } \\
\text { planta) }\end{array}$ & $\begin{array}{l}\text { Produtividade (kg } \\
\qquad \mathrm{ha}^{-1} \text { ) }\end{array}$ & $\begin{array}{l}\text { Fileiras de } \\
\text { grãos por } \\
\text { espiga }\end{array}$ & $\begin{array}{l}\text { Grãos por } \\
\text { fileira }\end{array}$ & $\begin{array}{c}\text { Massa de mil } \\
\text { grãos }(\mathrm{g})\end{array}$ \\
\hline Bloco & 2 & 17867509 ns & $0,009285 * *$ & $6823287 * *$ & $0,06^{\mathrm{ns}}$ & $78,00 * *$ & $139,69 *$ \\
\hline Pastejo (P) & 1 & $65104125 * *$ & $0,000135^{\mathrm{ns}}$ & $7515562 * *$ & 0,63 ns & $11,53 \mathrm{~ns}$ & 79,99 ns \\
\hline $\begin{array}{l}\text { Trat. de } \\
\text { Inverno (I) }\end{array}$ & 1 & $0,00^{\mathrm{ns}}$ & 0,002802 ns & $2076459^{\text {ns }}$ & $0,06^{\mathrm{ns}}$ & 12,81 ns & $481,67 * *$ \\
\hline $\begin{array}{l}\text { Trat. de } \\
\text { Verão (V) }\end{array}$ & 4 & $4810472^{\mathrm{ns}}$ & 0,001167 ns & $23086283 * *$ & $0,66^{\mathrm{ns}}$ & $79,29 * *$ & 67,37 ns \\
\hline Px I & 1 & $2604158^{\mathrm{ns}}$ & 0,002042 ns & $955657^{\mathrm{ns}}$ & $0,71^{\mathrm{ns}}$ & 16,62 ns & $94,00^{\mathrm{ns}}$ \\
\hline $\mathrm{P} \times \mathrm{V}$ & 4 & $5967885^{\text {ns }}$ & $0,001227^{\text {ns }}$ & 870861 ns & $0,17^{\mathrm{ns}}$ & $4,46^{\mathrm{ns}}$ & $130,26 *$ \\
\hline I x V & 4 & 904224 ns & $0,000852^{\mathrm{ns}}$ & $267001 \mathrm{~ns}$ & $0,17^{\mathrm{ns}}$ & 4,99 ns & $142,86 *$ \\
\hline$P \times I \times V$ & 4 & $5678525^{\mathrm{ns}}$ & 0,002092 ns & $483600^{\mathrm{ns}}$ & $0,18^{\mathrm{ns}}$ & 8,28 ns & $63,91 \mathrm{~ns}$ \\
\hline Erro & 38 & 7435585 & 0,001217 & 704526 & 0,26 & 6,11 & 38,48 \\
\hline Média & & 66944 & 0,9575 & 8510 & 16,13 & 33,21 & 286,03 \\
\hline CV (\%) & & 4,07 & 3,64 & 9,86 & 3,16 & 7,45 & 2,17 \\
\hline
\end{tabular}

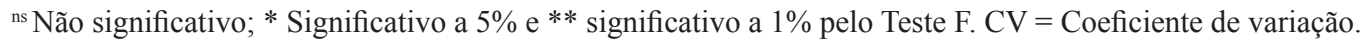

Fonte: Elaboração dos autores.

A população de plantas foi superior no tratamento com pastejo em relação à ausência de pastejo. Da mesma forma, a produtividade de grãos de milho foi superior nas áreas com pastejo em comparação as áreas sem pastejo, o que representa um incremento de 8,67\% (707 $\left.\mathrm{kg} \mathrm{ha}^{-1}\right)$. As demais variáveis não foram afetadas pelo pastejo (Tabela 3). Vários trabalhos têm demonstrado que o pastejo não tem prejudicado a produtividade das culturas em sucessão (ASSMANN et al., 2003; SANDINI et al., 2011), obviamente que isso se refere aqueles sistemas de produção manejados de forma adequada com ajuste da carga animal de acordo com a disponibilidade de forragem evitando-se sub e superpastejo de forma que isto possa acarretar degradação da pastagem e do solo. 
Tabela 3. População de plantas, índice de espigamento, produtividade, massa de mil grãos, número de fileiras de grãos por espiga e grãos por fileira de milho na presença e ausência de pastejo de aveia preta e azevém comum por ovinos no período de inverno e com e sem aplicação de cama de aviário na pastagem. Guarapuava, PR, 2011.

\begin{tabular}{|c|c|c|c|c|c|c|}
\hline Tratamento & $\begin{array}{l}\text { População } \\
\text { (plantas } \\
\text { ha }^{-1} \text { ) }\end{array}$ & $\begin{array}{c}\text { Índice de } \\
\text { espigamento } \\
\text { (espigas por planta) }\end{array}$ & $\begin{array}{l}\text { Produtividade } \\
\quad\left(\mathrm{kg} \mathrm{ha}^{-1}\right)\end{array}$ & $\begin{array}{l}\text { Grãos por } \\
\text { fileira }\end{array}$ & $\begin{array}{l}\text { Fileiras de } \\
\text { grãos por } \\
\text { espiga }\end{array}$ & $\begin{array}{l}\text { Massa de mil } \\
\text { grãos }(\mathrm{g})\end{array}$ \\
\hline Com pastejo & $67986 \mathrm{a}$ & $0,9590 \mathrm{a}$ & $8863 \mathrm{a}$ & $33,64 \mathrm{a}$ & $16,23 \mathrm{a}$ & $287,18 \mathrm{a}$ \\
\hline Sem pastejo & $65903 \mathrm{~b}$ & $0,9560 \mathrm{a}$ & $8156 b$ & $32,77 \mathrm{a}$ & $16,02 \mathrm{a}$ & $284,87 \mathrm{a}$ \\
\hline Média & 66944 & 0,9575 & 8510 & 33,21 & 16,13 & 286,03 \\
\hline $\begin{array}{l}\text { Com cama de } \\
\text { aviário }\end{array}$ & $66944 \mathrm{a}$ & 0,9507 a & $8695 \mathrm{a}$ & $33,67 \mathrm{a}$ & $16,16 \mathrm{a}$ & $288,85 \mathrm{a}$ \\
\hline $\begin{array}{l}\text { Sem cama de } \\
\text { aviário }\end{array}$ & $66944 \mathrm{a}$ & $0,9643 \mathrm{a}$ & $8323 \mathrm{a}$ & $32,74 \mathrm{a}$ & $16,00 \mathrm{a}$ & $283,19 \mathrm{~b}$ \\
\hline Média & 66944 & 0,9575 & 8510 & 536,27 & 33,21 & 286,03 \\
\hline
\end{tabular}

Médias seguidas por letras distintas nas colunas diferem entre si pelo Teste de Tukey a 5\% de probabilidade.

Fonte: Elaboração dos autores.

A produtividade de grãos de milho apresentou resposta quadrática em função do aumento da dose de cama de aviário no verão tanto para a presença como para a ausência de pastejo no inverno (Figura 1A). Pode-se observar que na ausência da adubação com cama de aviário no verão, as áreas com pastejo apresentaram produtividade de $7589 \mathrm{~kg} \mathrm{ha}^{-1}$, superior em $20,38 \%$ às áreas que não foram pastejadas que apresentaram produtividade de $6304 \mathrm{~kg} \mathrm{ha}^{-1}$. Além disso, com o aumento da dose de cama de aviário no verão a produtividade de milho manteve-se superior nas áreas com pastejo, atingindo a máxima eficiência técnica de $10931 \mathrm{~kg} \mathrm{ha}^{-1}$ com a aplicação de $12 \mathrm{Mg} \mathrm{ha}^{-1}$, o que corresponde a $270 \mathrm{~kg} \mathrm{ha}^{-1}$ de N. Enquanto que, nas áreas sem pastejo a produtividade máxima seria atingida com $9 \mathrm{Mg} \mathrm{ha}^{-1}\left(203 \mathrm{~kg} \mathrm{ha}^{-1}\right.$ de N) o que corresponderia a $10354 \mathrm{~kg} \mathrm{ha}^{-1}$ de grãos de milho. Ao comparar a máxima produtividade que poderia ser obtida nas áreas sem pastejo de 10354 $\mathrm{kg} \mathrm{ha}^{-1}$, pela equação de regressão, verifica-se que nas áreas com pastejo esta mesma produtividade seria alcançada com a aplicação de $7 \mathrm{Mg} \mathrm{ha}^{-1}$ o que representa uma economia de $2 \mathrm{Mg} \mathrm{ha}^{-1}$ de cama de aviário, equivalente a $45 \mathrm{~kg} \mathrm{ha}^{-1} \mathrm{de} \mathrm{N}$.

Estes resultados podem estar relacionados ao suprimento de nutrientes fornecido via adubação com cama de aviário. Uma vez que, autores como Oliveira et al. (2009) relataram que a adubação com $\mathrm{N}$ e P estimula o crescimento das plantas de milho o que pode afetar o rendimento da cultura. Além disso, deve-se considerar que o pastejo favorece a ciclagem dos nutrientes podendo estimular a sua absorção pelas plantas, possibilitando, desta forma, maior aproveitamento dos nutrientes aplicados, quando comparado às áreas que não foram pastejadas. Nesse contexto, cabe destacar que nas áreas sem pastejo havia maior quantidade de fitomassa e que pela elevada relação $\mathrm{C} / \mathrm{N}$ de gramíneas forrageiras como a aveia e azevém, a decomposição dos resíduos vegetais é mais lenta além de ocorrer maior imobilização de N. A imobilização de N por gramíneas antecessoras a cultura do milho foi relatada por Silva et al. (2007a). 
Figura 1. Produtividade de grãos de milho (A), número de grãos por fileira $(B)$ e massa de mil grãos $(C$ e $D)$ em função das doses de cama de aviário aplicadas no verão. NS: não significativo, ** significativo a 1\% de probabilidade. Guarapuava, PR, 2010.
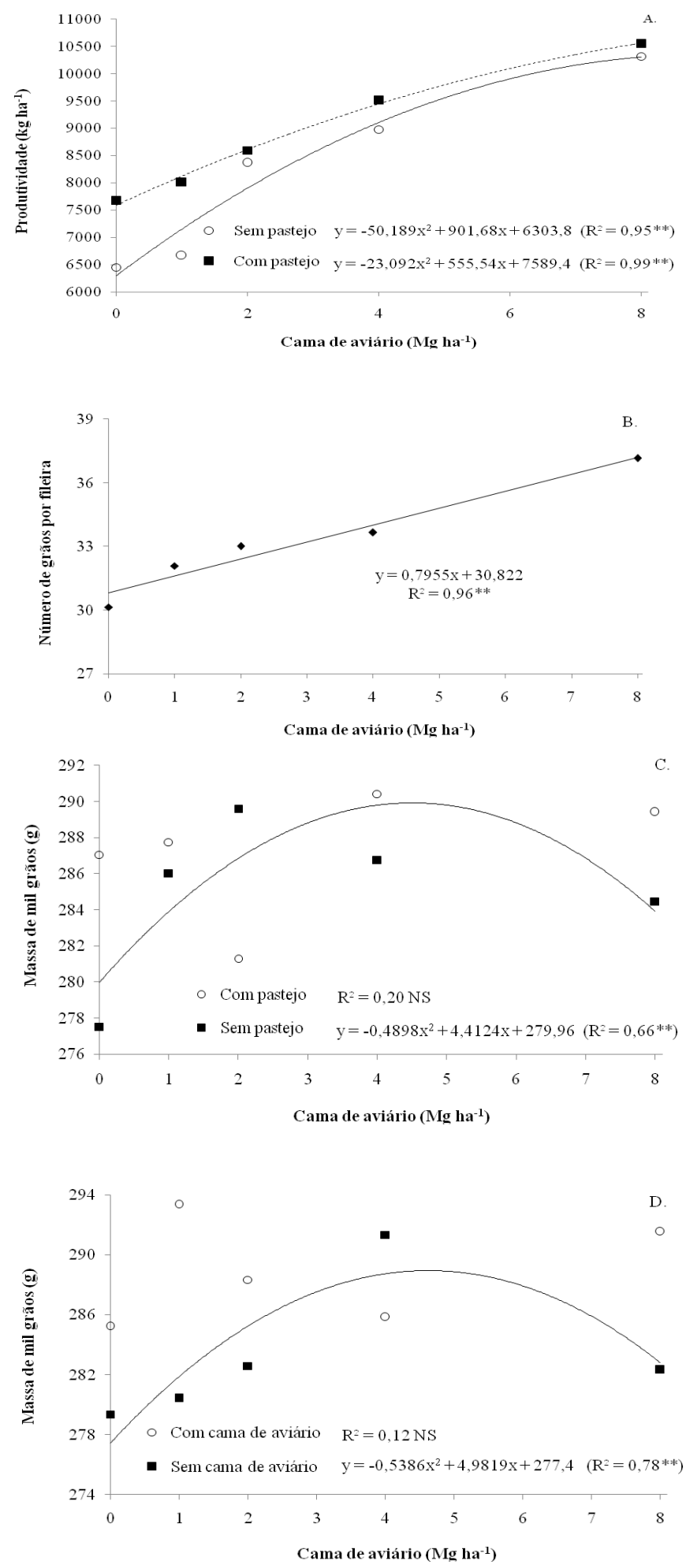

Fonte: Elaboração dos autores. 
A produtividade do milho em função de doses de cama de aviário também foi explicada por uma equação quadrática por Bayer, Ceretta e Schneider (1999) sendo a dose de máxima eficiência econômica estimada em $9,8 \mathrm{Mg} \mathrm{ha}^{-1}$. Hanish et al. (2009) também relataram efeito positivo pela adubação com cama de aviário com incremento na produtividade de milho quando compararam o uso de cama de aviário com a aplicação de uréia natural, urina de vaca, consórcio com mucuna cinza e da testemunha. De forma semelhante ao constatado neste trabalho com a cultura do milho, Gewehr et al. (2010) verificaram que o modelo quadrático foi o que melhor se ajustou ao rendimento de massa verde de capim elefante em função das doses crescentes de cama de aviário, constatando que para se obter em torno de $50 \mathrm{Mg} \mathrm{ha}^{-1}$ de capim elefante a dose de $240 \mathrm{~kg} \mathrm{ha}^{-1}$ de $\mathrm{N}$ originado de cama de aviário foi a recomendada, o que corresponde a $9562 \mathrm{~kg}$ ha $^{-1}$ considerando o teor de $2,51 \%$ de $\mathrm{N}$ do material avaliado.

Na média dos tratamentos, a aplicação de $5 \mathrm{Mg}$ $\mathrm{ha}^{-1}$ de cama de aviário no inverno proporcionou aumento na massa de mil grãos de milho em relação à ausência da adubação (Tabela 3), o que evidencia efeito residual da adubação no inverno. E, embora tal aspecto não tenha se refletido de forma significativa na produtividade de grãos, constatouse tendência de aumento na produtividade de milho com a adubação com cama de aviário na pastagem de $8323 \mathrm{~kg} \mathrm{ha}^{-1}$ para $8695 \mathrm{~kg} \mathrm{ha}^{-1}$. Efeito residual da adubação na pastagem de inverno sobre a cultura sucessora já foram relatados por Assmann et al. (2003) e Sandini et al. (2011).

Silva et al. (2007b) avaliaram a produtividade de milho em diferentes sistemas de produção e concluíram que o sistema orgânico com adição de $40 \mathrm{~m}^{3}$ ou 14,33 $\mathrm{Mg} \mathrm{ha}^{-1}$ de composto orgânico foi superior ao sistema mineral e ao sistema sem adubação, e em alguns casos, é igual ao sistema organomineral. Os autores também verificaram que o uso contínuo de adubação organomineral na cultura do milho por vários anos provoca aumentos significativos na produção de grãos.

Para Hoffmann et al. (2001), os benefícios no uso de estercos animais podem ser assim elencados: melhorias nas propriedades físicas do solo e no fornecimento de nutrientes, aumento no teor de matéria orgânica, melhorando a infiltração da água como também aumentando a capacidade de troca de cátions.

De acordo Konzen (1999), a adubação orgânica tem proporcionado produção de grãos igual ou superior aos da adubação química equivalente, sendo que em áreas de Cerrado onde se faz adubações orgânicas por vários períodos culturais manifestam forte atividade de minhocas nativas, o que representa um grande benefício para a qualidade física, biológica e da fertilidade do solo, principalmente pela manutenção e aumento da matéria orgânica do solo.

O número de grãos por fileira apresentou resposta linear crescente com o aumento da dose de cama de aviário no verão (Figura 1B). A massa de mil grãos apresentou resposta quadrática com o aumento da dose de cama de aviário no verão na ausência de pastejo no inverno, ao passo que, não houve significância na presença de pastejo (Figura 1C). Na ausência de cama de aviário no inverno a massa de mil grãos apresentou comportamento quadrático com aumento da dose de cama de aviário no verão. No entanto, com $5 \mathrm{Mg} \mathrm{ha}^{-1}$ de cama de aviário no inverno não ocorreu resposta significativa com o uso da cama de aviário no verão (Figura 1D). Em trabalho de Silva et al. (2005), realizado com o estudo de doses de $\mathrm{N}$ em cobertura no milho, foi verificado aumento do número de fileiras, grãos por fileira, grãos por espiga e massa de mil grãos com o incremento da dose de $\mathrm{N}$ na cultura, o que pode estar relacionado com os resultados obtidos neste trabalho, uma vez que, a cama de aviário pode fornecer vários nutrientes, com destaque para o N. Leite et al. (2003) verificaram que a presença de adubação orgânica aumentou os estoques de C orgânico e $\mathrm{N}$ total, em relação aos sistemas de 
produção com adubação mineral ou mesmo sem adubação, o que a posiciona como uma estratégia de manejo importante para a conservação da qualidade do solo. No entanto, a aplicação do composto orgânico constituiu uma forma efetiva de reciclagem de nutrientes e retorno de $\mathrm{C}$ ao solo. Fioreze e Ceretta (2006) constataram que a cama de aviário, por conter maior quantidade de nutrientes, é uma alternativa melhor do que a cama de suínos, tanto técnica quanto economicamente para a cultura da batata.

Segundo Konzen (2003), o resíduo de um sistema pode constituir-se em insumo para outro sistema produtivo, para tanto, faz-se necessário a associação de diversos componentes da cadeia produtiva em sistemas integrados, sustentáveis social e economicamente, e que preservem o meio ambiente. Logo, a partir dos resultados apresentados verificou-se potencial de uso da cama de aviário para adubação orgânica em sistema de integração lavoura-pecuária, o que possibilita intensificação do uso da área e com incremento na produtividade da cultura do milho.

A partir dos resultados obtidos neste trabalho pode-se concluir que há efeito residual da cama de aviário aplicada na pastagem durante o inverno sobre a cultura do milho em sucessão no verão. A adubação com cama de aviário no milho apresenta viabilidade técnica por proporcionar aumento na produtividade da cultura, logo, a cama de aviário pode ser uma alternativa de adubação orgânica para a cultura do milho em sistema de integração lavoura-pecuária.

\section{Referências}

ASSMANN, J. M.; BRAIDA, J. A.; CASSOL, L. C.; MAGIERO, E. C.; MANTELI, C.; GRIZ, E. Produção de matéria seca de forragem e acúmulo de nutrientes em pastagem anual de inverno tratada com esterco líquido de suínos. Ciência Rural, Santa Maria, v. 39, n. 8, p. 24082416, 2009.
ASSMANN, T. S.; ASSMANN, A. L.; ASSMANN, J. M. Ciclagem de nutrientes e adubação. In: ASSMANN, A. L.; SOARES, A. B.; ASSMANN, T. S. (Ed). Integração lavoura-pecuária para a agricultura familiar. Londrina: IAPAR, 2008. p. 16-24.

ASSMANN, T. S.; ROZELLI JUNIOR, P.; MORAES, A.; ASSMANN, A. L.; KOEHLER, H. S.; SANDINI, I. Rendimento de milho em área de integração lavourapecuária sob o sistema de plantio direto, em presença e ausência de trevo branco, pastejo e nitrogênio. Revista Brasileira de Ciência do Solo, Viçosa, MG, v. 27, n. 4, p. 675-683, 2003.

BAYER, C.; CERETTA, C. A.; SCHNEIDER, N. G. Viabilidade da utilização de cama de aviário como fertilizante na cultura do milho. Revista Cientifica Rural, Santa Maria, v. 2, n. 1, p. 10-14, 1999.

BRAZ, S. P.; NASCIMENTO JUNIOR, D. do; CANTARUTTI, R. B.; REGAZZI, A. J.; MARTINS, C. E.; FONSECA, D. M. da; BARBOSA, R. A. Aspectos quantitativos do processo de reciclagem de nutrientes pelas fezes de bovinos sob pastejo em pastagem de Brachiaria decumbens na zona da mata de Minas Gerais. Revista Brasileira Zootecnia, Viçosa, v. 31, n. 2, p. 858865, 2002.

COSTA, A. M.; BORGES, E. N.; SILVA, A. de A.; NOLlA, A.; GUIMARÃES, E. C. Potencial de recuperação física de um Latossolo Vermelho, sob pastagem degradada influenciado pela aplicação de cama de frango. Ciência e Agrotecnologia, Lavras, v. 33, p. 1991-1998, 2009. Especial.

CRUZ, J. C.; KONZEN, E. A.; PEREIRA FILHO, I. A.; MARRIEL, I. E.; CRUZ, I.; DUARTE, J. O.; OLIVEIRA, M. F.; ALVARENGA, R. C. Produção de milho orgânico na agricultura familiar. Sete Lagoas, MG: Embrapa, 2006. 17 p. (Circular técnica, 81).

EMPRESA BRASILEIRA DE PESQUISA AGROPECUÁRIA - EMBRAPA. Centro Nacional de Pesquisa de Solos (Rio de Janeiro, RJ). Sistema brasileiro de classificação de solos. 2. ed. Rio de Janeiro: Embrapa Solos, 2006.

FERNANDES, F. C. S.; LIBARDI, P. L.; TRIVELIN, P. C. O. Parcelamento da adubação nitrogenada na cultura do milho e utilização do $\mathrm{N}$ residual pela sucessão aveia preta - milho. Ciência Rural, Santa Maria, v. 38, n. 4, p. 1138-1141, 2008.

FIOREZE, C.; CERETTA, C. A. Fontes orgânicas de nutrientes em sistemas de produção de batata. Ciência Rural, Santa Maria, v. 36, n. 6, p. 1788-1793, 2006. 
GEWEHR, C. E.; FOLLMANN, D. D.; ROSNIECEK, M.; COSTENARO, J.; PAGNO, G. Rendimento do capim elefante com adubação orgânica para uso em cama de aviário. Revista Brasileira de Agroecologia, Bahia, v. 5, n. 1, p. 32-36, 2010.

GRACIANO, J. D.; HEREDIA ZÁRATE, N. A.; VIEIRA, M. C.; ROSA, Y. B. C. J.; SEDIYAMA, M. A.; RODRIGUES, E. T. Efeito da cobertura do solo com cama-de-frango semidecomposta sobre dois clones de mandioquinha-salsa. Acta Scientiarum Agronomy, Maringá, v. 28, n. 3, p. 365-371, 2006.

HANISH, A. L.; FONSECA, J. A.; ALMEIDA, E. de. Efeito do uso de diferentes estratégias de manejo agroecológico no desempenho produtivo da cultura do milho. Revista Brasileira de Agroecologia, Bahia, v. 4, n. 2, p. 1631-1634, 2009.

HOFFMANN, I.; GERLING, D.; KYIOGWOM, U. B.; MANÉ-BIELFELDT, A. Farmers management strategies to maintain soil fertility in a remote area in northwest Nigeria. Agriculture, Ecosystems and Environment, v. 86, n. 3, p. 263-275, 2001.

INSTITUTO AGRONÔMICO DO PARANÁ - IAPAR. Cartas climáticas do Paraná: classificação climática. Deisponível em: <http://www.iapar.br/modules/conteudo/ conteudo.php? conteudo=863>. Acesso em: 09 ago. 2010.

KONZEN, E. A. Fertilização de lavoura e pastagem com dejetos de suínos e cama de aviário. Sete Lagoas, MG: Embrapa Milho e Sorgo, 2003. (Circular técnica, 31).

Estabilização de resíduos orgânicos em processos de compostagem e vermicompostagem. Sete Lagoas: Embrapa, CNPMS, 1999. 6 p. (Comunicado técnico, 12).

LEITE, L. F. C.; MENDONÇA, E. S.; NEVES, J. C. L.; MACHADO, P. L. A. O.; GALVÃO, J. C. C. Estoques totais de carbono orgânico e seus compartimentos em Argissolo sob floresta e sob milho cultivado com adubação mineral e orgânica. Revista Brasileira de Ciência do Solo, Viçosa, MG, v. 27, n. 5, p. 821-832, 2003.

MEllo, S. C.; VITTI, G. C. Desenvolvimento do tomateiro e modificações nas propriedades químicas do solo em função da aplicação de resíduos orgânicos, sob cultivo protegido. Horticultura Brasileira, Brasília, v. 20, n. 2, p. 200-206, 2002.
MENEZES, J. F. S.; FREITAS, K. R.; CARMO, M. L. do; SANTANA, R. O.; FREITAS, M. B. de; PERES, L. C. Produtividade de massa seca de forrageiras adubadas com cama de frango e dejetos líquidos de suínos. In: SIMPÓSIO INTERNACIONAL SOBRE GERENCIAMENTO DE RESÍDUOS DE ANIMAIS, 1., 2009, Florianópolis. Anais... Florianópolis, SC: Concórdia, Embrapa Aves e Suínos, 2009.

MOTT, G. E.; LUCAS, H. L. The design, conduct en interpretation of grazing trials on cultivated and improved pastures. In: INTERNATIONAL GRASSLAND CONGRESS, 6., 1952. Proceedings... Pensylvania: State College, 1952. p. 1380-1395.

OLIVEIRA, F. A. de; CAVALCANTE, L. F.; SILVA, I. de F. da; PEREIRA, W. E.; OLIVEIRA, J. C. de; FILHO, J. F. da C. Crescimento do milho adubado com nitrogênio e fósforo em um Latossolo Amarelo. Revista Brasileira de Ciências Agrárias, Recife, v. 4, n. 3, p. 238-244, 2009.

SANDINI, I. E.; MORAES, A. de; PELISSARI, A.; NEUMANN, M.; FALBO, M. K.; NOVAKOWISKI, J. H. Efeito residual do nitrogênio na cultura do milho no sistema de produção integração lavoura-pecuária. Ciência Rural, Santa Maria, v. 41, n. 8, p. 1315-1322, 2011.

SILVA, A. A. da; SILVA, P. R. F. da; SUHRE, E.; ARGENTA, G.; STRIEDER, M. L.; RAMBO, L. Sistemas de coberturas de solo no inverno e seus efeitos sobre o rendimento de grãos do milho em sucessão. Ciência Rural, Santa Maria, v. 37, n. 4, p. 928-935, 2007a.

SILVA, E. C. da; BUZETTI, S.; GUIMARÃES, G. L.; LAZARINI, E.; SÁ, M. E. Doses e épocas de aplicação de nitrogênio na cultura do milho em plantio direto sobre Latossolo Vermelho. Revista Brasileira de Ciência do Solo, Viçosa, MG, v. 29, n. 3, p. 353-362, 2005.

SILVA, R. G.; GALVÃO, J. C. C.; MIRANDA, G. V.; SILVA, D. G.; ARNHOLD, E. Produtividade de milho em diferentes sistemas produtivos. Revista Verde, Mossoró, v. 2, n. 2, p. 136-141, 2007 b. 